\title{
Dumb-bell lipoma of finger digital flexor sheath: Unusual presentation
}

Sir,

Lipomas are common benign mesenchymal tumours arising from the adipose tissue predominantly involving the trunk and head and neck region. ${ }^{[1,2]}$ Lipoma of hand comprises $1 \%$ of all lipomas occurs in our body though the exact incidence of finger lipoma not found in the literature. There are few case reports of finger flexor tendon sheath lipoma available, but none of them mentioned about the dumb-bell-shaped presentation of lipoma in finger which presented on the both sides of flexor tendon. ${ }^{[3]}$ Lipoma of the hand and fingers may be divided into 'endovaginal' (origin from the tendon sheath), 'epivaginal' (origin from other subaponeurotic soft tissues) and parosteal (arising from the periosteum). ${ }^{[3-5]}$ Endovaginal lipomas can be further divided into 'lipoma simplex symmetricum' and 'lipoma arborescens'.

Our patient is 65 years aged female, presented with the complaint of slow-growing swelling in the right ring finger over the period of 10 years. There was no history of pain and reduction strength of the finger grip except for the past 6 months, in which she was feeling the difficulty in flexing the ring finger completely. On examination, a solitary, soft, lobulated swelling of size $4.5 \mathrm{~cm} \times 3 \mathrm{~cm} \times 3 \mathrm{~cm}$ extending proximally from the distal palmar crease to the proximal interphalangeal joint crease of the fourth ray. The swelling found to extend dorsally through the third and fourth web spaces [Figure 1]. Swelling was not attached to the skin, and the movements of flexor tendons did not affect the swelling significantly. Complete flexion of the finger was restricted. There was no sensory abnormality in the digit. The patient was having candidiasis infection of the third and fourth web space. Magnetic- resonance imaging showed the confirmed the diagnosis and showed the extent of the lesion [Figure 2].

The patient was treated with topical antifungals for the candidiasis infection. Under general anaesthesia, tourniquet control and loupe magnification, Brunner's skin incision was made and flaps raised. A lobulated lipoma arising from the flexor tendon sheath extending both ulnar and radial sides (Dumb-bell shaped) of ring finger through the first cruciate pulley (C1) with a communicating segment posterior to the flexor tendons [Figure 3a and b] was noticed. The swelling was extending dorsally displacing the neurovascular bundle on both sides and was dissected and delivered into the wound, safeguarding the neurovascular 

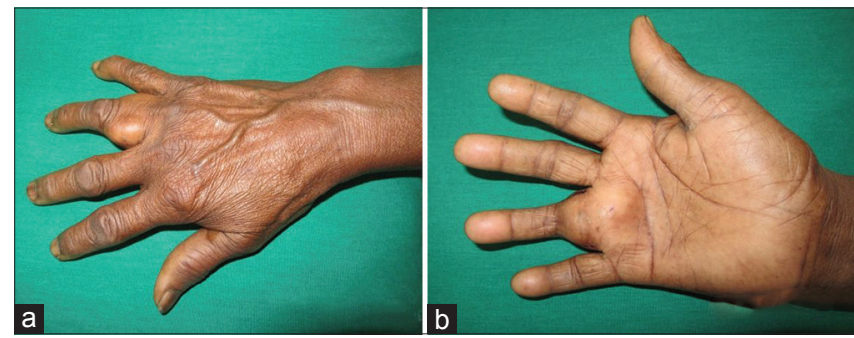

Figure 1: Lipoma right ring finger, (a) palmar and, (b) dorsal aspect

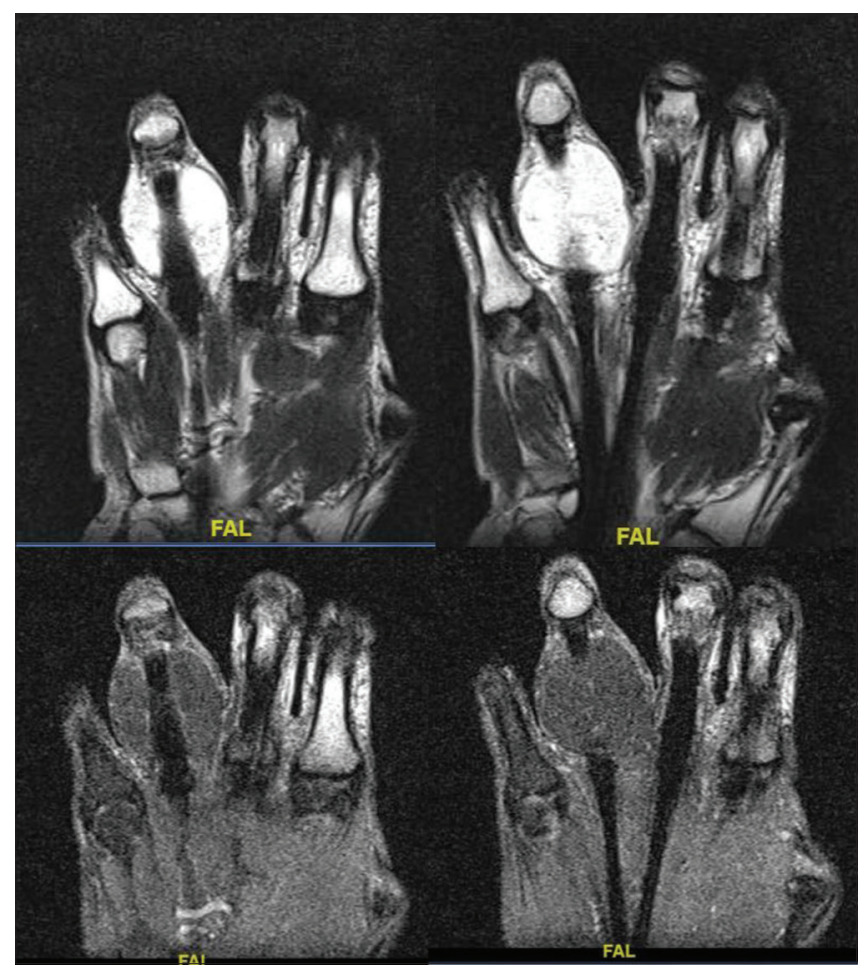

Figure 2: T1- and T2-weighted magnetic- resonance imaging images showing the lipoma and its extent

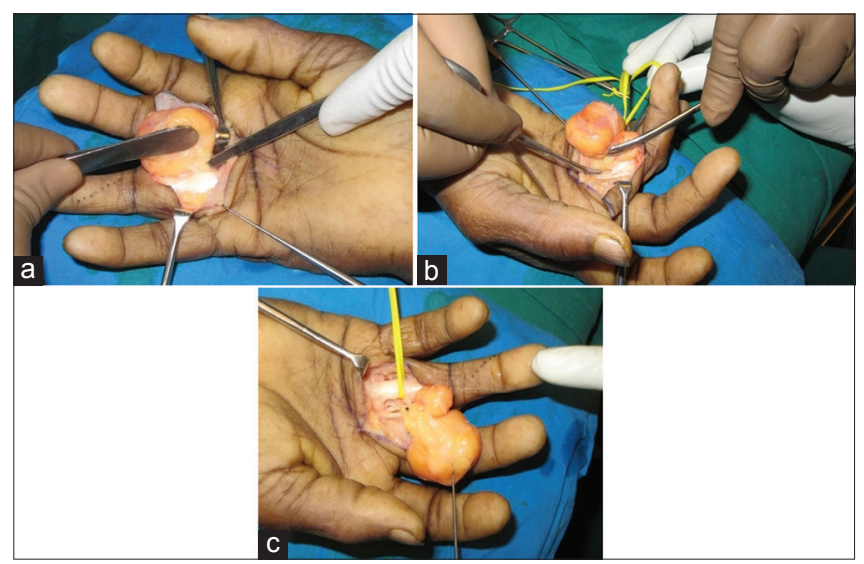

Figure 3: (a) Lipoma seen on the both sides of flexor tendon. (b) Communicating segment of lipoma extends through cruciate pulley posterior to the flexor tendons. (c) Excision of dumb-bell-shaped lipoma along with digital sheath

bundles. Cruciate pulley (C1) was released completely on the both sides, flexor tendons were retracted and the lipoma along with the part of synovial sheath excised [Figure 3c].
Histopathological examination of the specimen confirmed lipoma. Post-operative course was uneventful.

This case is reported because of its unusual presentation. Careful preoperative and intraoperative assessment is required so as not to miss the intrasynovial communicating segment, which may cause future recurrence if left behind.

\section{Financial support and sponsorship}

Department of plastic Surgery, Jawaharlal Institute of Postgraduate Medical Education and Research, Pondicherry, India.

\section{Conflicts of interest}

There are no conflicts of interest.

\section{Elankumar Subbarayan, Devi Prasad Mohapatra, Sudhanva Hemant Kumar, Preethitha Babu, Senthil Kumaran}

Department of Plastic Surgery, Jawaharlal Institute of Postgraduate Medical Education and Research,

Puducherry, India

Address for correspondence:

Dr. Elankumar Subbarayan,

Department of Plastic Surgery, Jawaharlal Institute of Postgraduate Medical Education and Research, Puducherry - 605 006, India. E-mail: dr.elankar86@gmail.com

\section{REFERENCES}

1. Enzinger FM, Weiss SW. Soft Tissue Tumors. St. Louis: Mosby; 1995;3:381-430.

2. Allen PW. Tumors and Proliferations of Adipose Tissue. New York: Masson; 1981.

3. Bryan RS, Dahlin DC, Sullivan CR. Lipoma of the tendon sheath J Bone Joint Surg Am 1956;38-A:1275-80.

4. Straus FH. Deep lipomas of the hand. Ann Surg 1931;94:269-73.

5. Kitagawa Y, Tamai K, Kim Y, Hayashi M, Makino A, Takai S, et al. Lipoma of the finger with bone erosion. J Nippon Med Sch 2012;79:307-11

This is an open access article distributed under the terms of the Creative Commons Attribution-NonCommercial-ShareAlike 3.0 License, which allows others to remix, tweak, and build upon the work non-commercially, as long as the author is credited and the new creations are licensed under the identical terms.

\begin{tabular}{|l|l|}
\hline \multicolumn{2}{|c|}{ Access this article online } \\
\hline Quick Response Code: & Website: \\
\hline
\end{tabular}

How to cite this article: Subbarayan E, Mohapatra DP, Kumar SH, Babu P, Kumaran S. Dumb-bell lipoma of finger digital flexor sheath: Unusual presentation. Indian J Plast Surg 2017;50:320-1.

(ㄷ) 2017 Indian Journal of Plastic Surgery | Published by Wolters Kluwer - Medknow 